\title{
Standard for the Exchange of Nonclinical Data Implementation Guide Version
}

National Cancer Institute

\section{Source}

National Cancer Institute. Standard for the Exchange of Nonclinical Data Implementation

Guide Version. NCI Thesaurus. Code C90458.

The version of the Standard for the Exchange of Non-clinical Data that is being used in the study. 